Retraction

\title{
Retracted: The Antioxidant and Starch Hydrolase Inhibitory Activity of Ten Spices in an In Vitro Model of Digestion: Bioaccessibility of Anthocyanins and Carotenoids
}

\section{Evidence-Based Complementary and Alternative Medicine}

Received 25 August 2016; Accepted 25 August 2016

Copyright (c) 2016 Evidence-Based Complementary and Alternative Medicine. This is an open access article distributed under the Creative Commons Attribution License, which permits unrestricted use, distribution, and reproduction in any medium, provided the original work is properly cited.

Evidence-Based Complementary and Alternative Medicine has retracted the article titled "The Antioxidant and Starch Hydrolase Inhibitory Activity of Ten Spices in an In Vitro Model of Digestion: Bioaccessibility of Anthocyanins and Carotenoids" [1], as the High Performance Liquid Chromatography (HPLC) results were questioned and it was found that the underlying data for this study are not available, and thus the results of the article are questionable.

\section{References}

[1] N. Jayawardena, M. I. Watawana, R. T. Jayathilaka, and V. Y. Waisundara, "The antioxidant and starch hydrolase inhibitory activity of ten spices in an in vitro model of digestion: bioaccessibility of anthocyanins and carotenoids," Evidence-Based Complementary and Alternative Medicine, vol. 2015, Article ID 764238, 9 pages, 2015. 